\title{
Cuidado com a cefaleia crônica diária!
}

\section{Be careful with the chronic daily headache!}

Paulo Sergio Faro Santos

Neurologista, Chefe do Setor de Cefaleia e Dor Orofacial, Departamento de Neurologia, Instituto de Neurologia de Curitiba

Faro Santos PS. Cuidado com a cefaleia crônica diária! Headache Medicine. 2018;9(1):33-34

\section{INTRODUÇÃO}

Muito se ouve sobre pacientes com cefaleia crônica diária (CCD) na rotina do neurologista. Nessa situação sempre me questiono se os profissionais entendem o termo a que se referem. CCD na verdade não é um diagnóstico, mas a presença de toda e qualquer cefaleia com frequência de pelo menos 15 dias no mês por no mínimo três meses, ou seja, é um termo genérico.

Compreende-se a utilização da expressão CCD no período em que foi rotulada pela primeira vez, final da década de 1970 ou início da década de 1980, provavelmente pelo médico italiano Federigo Sicuteri.(1) $\mathrm{Na}$ época ainda não havia uma normatização diagnóstica para as cefaleias. A primeira edição da classificação internacional das cefaleias, ou International Classification of Headache Disorders (ICHD) - termo mais utilizado, ocorreu apenas em 1988. (2) Atualmente utilizamos a terceira edição desta classificação que foi publicada neste ano (2018). ${ }^{(3)}$

Para entendermos melhor, a ICHD nas suas três edições publicadas até o momento nunca utilizou o termo cefaleia crônica diária como diagnóstico nosológico. (2-4) Eis o cerne da questão, na rotina médica, o termo CCD está sendo utilizado com este sentido.

Diante de um indivíduo que se enquadra nos critérios de CCD, o profissional deverá submetê-lo primeiramente a uma anamnese completa. Em regra geral, toda cefaleia crônica um dia foi episódica, desta maneira precisa-se descobrir o padrão da cefaleia previamente ao período de piora, a fim de auxiliar no diagnóstico da atual cefaleia cronificada. Além disso, deve-se buscar por sinais de alerta na história, no exame físico, neurológico e cefaliátrico, no intuito de definir a necessidade de exames complementares, se houver suspeita de cefaleia secundária. ${ }^{(5)}$ Após exclusão de causas secundárias, as CCDs podem ser divididas em cefaleias de curta duração e de longa duração, de acordo com suas manifestações clínicas (Tabela 1). ${ }^{(6)}$

Tabela 1 - Diagnóstico diferencial entre as cefaleias crōnicas diárias

\begin{tabular}{ll}
\hline CCD de curta duração & CCD de longa duração \\
\hline Cefaleia em salvas crônica & Migrânea crônica \\
Hemicrânia paroxistica crônica & $\begin{array}{l}\text { Cefaleia tipo tensional crônica } \\
\text { Hemicrânia continua }\end{array}$ \\
$\begin{array}{l}\text { Short-lasting unilateral } \\
\text { neuralgiform headaches with } \\
\text { conjunctival injection and } \\
\text { tearing (SUNCT) syndrome }\end{array}$ & \\
$\begin{array}{l}\text { Short-lasting unilateral } \\
\text { neuralgiform headaches } \\
\text { with autonomic symptoms but } \\
\text { without lacrimation and } \\
\text { conjunctival injection (SUNA) } \\
\text { Cefaleia hipnica }\end{array}$ & $\begin{array}{l}\text { Cefaleia persistente diária desde } \\
\end{array}$ \\
\hline
\end{tabular}

Um estudo populacional americano revelou que, apesar de atualmente termos disponível a ICHD, pouco mais da metade dos indivíduos que possuíam o diagnóstico de migrânea foram erroneamente diagnosticados com cefaleia tipo tensional, cefaleia atribuída à sinusopatia e cefaleia em salvas. ${ }^{(7)}$

O diagnóstico incorreto levará o paciente a fazer uso de medicações inadequadas para sua cefaleia e, por conseguinte, acarretará em persistência e até agravamento dos seus sintomas. Se pensarmos que em casos de hemicrânia contínua e hemicrânia paroxística crônica o 
tratamento mais indicado é a indometacina, na cefaleia tipo tensional crônica são os antidepressivos e para indivíduos com migrânea crônica os anticonvulsivantes, a toxina botulínica e, mais recentemente, os anticorpos monoclonais contra o peptídeo relacionado ao gene da calcitonina (CGRP) ou seu receptor, entenderemos a importância de não se utilizar o termo $C C D$, mas sim buscar o diagnóstico.

Sabe-se que as cefaleias são um problema de saúde pública e que implicam custos diretos e indiretos ao indivíduo e ao sistema de saúde público e/ou privado. $\bigcirc$ custo indireto ocorre principalmente pelo absenteísmo, por exemplo, a migrânea é a terceira principal causa de incapacidade em pessoas abaixo dos 50 anos e a cefaleia atribuída ao uso excessivo medicamentoso está dentre as vinte doenças mais incapacitantes. Em relação aos custos diretos, estão inclusos os custos das medicações e a solicitação desnecessária de exames complementares, principalmente de neuroimagem. ${ }^{(8)}$

Diante deste complexo cenário, recomenda-se que cada vez mais o neurologista se familiarize com os critérios diagnósticos das principais cefaleias primárias e lembre-se de consultar a ICHD em suspeita de cefaleias menos comuns. Assim, o diagnóstico será feito de maneira assertiva, os exames complementares, se necessários, não serão realizados aleatoriamente e o tratamento será direcionado, de maneira a reduzir a incapacidade do paciente.

\section{REFERÊNCIAS}

1. Sjaastad $\bigcirc$. "Chronic daily headache" ("Cefalea crônica quotidiana"). Cephalalgia. 1985; 5 Suppl 2:191-3.

2. Classification and diagnostic criteria for headache disorders, cranial neuralgias and facial pain. Headache Classification Committee of the International Headache Society. Cephalal gia. 1988;8 (Suppl 7): 1-96.

3. Headache Classification Committee of the International Headache Society. The International Classification of Headache Disorders (3rd edition). Cephalalgia. 2018; 38 (3rd edition): $1-211$.

4. Headache Classification Subcommittee of the International Headache Society. The International Classification of Headache Disorders: 2nd edition. Cephalalgia. 2004;24 Suppl 1:9-160.

5. Sheeler RD, Garza I, Vargas BB, O'Neil AE. Chronic Daily Headache: Ten Steps for Primary Care Providers to Regain Control. Headache. 2016. 56(10):1675-1684.

6. Halker RB, Hastriter EV, Dodick DW. Chronic Daily Headache: An Evidence-Based and Systematic Approach to a Challenging Problem. Neurology ${ }^{\circledR}$ Clinical Practice 2011;76 (Suppl2):S37-S43.
7. Lipton RB, Diamond S, Reed M, Diamond ML, Stewart WF. Migraine diagnosis and treatment: results from the American Migraine Study II. Headache. 2001; 4 1: 638-645.

8. Mennini FS, Gitto L. The costs of headache disorders. J Headache Pain. 2015; 16(Suppl 1): A3.

Correspondência

Paulo Sergio Faro Santos dr.paulo.faro@gmail.com

Recebido: 7 de março de 2018

Aceito: 28 de março de 2018 